\title{
Retraction Note: Climate environment of coastline and urban visual communication art design from the perspective of GIS
}

\section{Cancan $\mathrm{Yu}^{1}$}

Published online: 22 November 2021

C) Saudi Society for Geosciences 2021

Retraction Note: Arabian Journal of Geosciences (2021) 14: 310 https://doi.org/10.1007/s12517-021-06692-5

The Editor-in-Chief and the Publisher have retracted this article because the content of this article is nonsensical. The peer review process was not carried out in accordance with the Publisher's peer review policy. The author has not responded to correspondence regarding this retraction.

The original article can be found online at https://doi.org/10.1007/ s12517-021-06692-5

Cancan $\mathrm{Yu}$

kenyuycc@sina.com

1 School of Digital Creation \& Animation, Shenzhen Polytechnic, Shenzhen 518055, Guangdong, China 